\title{
Cultural Diversity, Country Size, And The IFRS Adoption Decision
}

Curtis E. Clements, Abilene Christian University, USA

John D. Neill, Abilene Christian University, USA

O. Scott Stovall, Abilene Christian University, USA

\begin{abstract}
In this paper, we empirically examine the International Financial Reporting Standards (IFRS) adoption decision of 61 countries in an attempt to determine why some countries have adopted IFRS while others, at least to this point in time, have chosen not to adopt. In particular, we examine the influence of cultural diversity and country size on the adoption decision. Our results indicate that the IFRS adoption decision is significantly related to the size of the country, while we are unable to document any cultural influences on the decision. Our chief result is that larger countries are less likely to adopt International Financial Reporting Standards than small countries. This result is consistent with the notion that larger countries have a well-established set of financial accounting and reporting standards already in place, and therefore would be reluctant to incur the costs of changing to an international set of standards.
\end{abstract}

Keywords: Accounting, Culture, Financial Reporting, IFRS

\section{INTRODUCTION}

1 n 2001, the International Accounting Standards Board (IASB) was created with an expressed purpose of creating a single global set of accounting and reporting standards (IASB, 2009). The IASB's authoritative pronouncements governing international financial reporting are known as International Financial Reporting Standards (IFRS). While over 100 countries have adopted the international standards, many have not - including the United States (IASB, 2009). While many countries, including the U.S., have expressed a desire and tentative plans for convergence with IASB standards, barriers apparently exist which have, at least to this point, prevented world-wide acceptance of international accounting standards. The goal of this research is to examine such possible impediments to the universal adoption of IFRS. Specifically, in this study, we will examine whether cultural and size differences across countries are empirically related to countries' decisions about whether to adopt IFRS or not.

In related research, we previously examined cultural and socioeconomic influences on national accounting organizations' decisions about whether to adopt the International Federation of Accountants' model code of ethics (Clements et al., 2009a; Clements et al., 2009b). In this paper, we extend our prior studies by empirically examining how cultural factors and country size influence another decision about whether to adopt an international set of standards, namely IFRS.

Our results are mixed. While we are unable to document significant cultural differences between IFRS adopters and non-adopters, our results indicate that the IFRS adoption decision is negatively related to the size of the country, whether size is measured by market capitalization or population. Specifically, to this date, many of the largest countries in the world have not adopted International Financial Reporting Standards. It seems plausible that large countries in terms of population and/or market capitalization may have highly developed accounting standards already in place that have withstood the test of time, and that such countries might be resistant to discarding their current accounting standards in order to adopt IFRS. Accounting standards setting bodies in larger countries might also have to deal with a greater number of accounting constituencies, making it more difficult to change from the status quo in such a significant way as adopting a new set of accounting standards. In such cases, the cost of 
converting from a country-specific set of standards to IFRS would be high. Conversely, smaller countries may not have the socioeconomic wherewithal to develop and administer their own accounting standards, and would therefore be more likely to adopt the international standards developed by the IASB.

\section{MOTIVATION AND PRIOR LITERATURE}

This appears to be an important and largely unexamined area of international accounting research. Empirical examinations of the impact of culture on the adoption of international accounting standards are few in number. However, Doupnik and Tsakumis $(2004$, p. 2) stress the importance of just such examinations when they state, "In the context of financial reporting, the important question is whether financial reporting models and practices are universal or if their international applicability is constrained by difference in culture." We believe that it is important to examine whether cultural differences might serve as impediments to the universal adoption of international accounting standards. If such factors are discovered to indeed impede global IFRS adoption, then the results of this study could be used as a first step in the process of determining how to overcome these impediments.

Ramanna and Sletten (2009) conduct a comprehensive study of the issue of why some countries have adopted IFRS and some have not. Included in their analysis is an examination of whether cultural influences can help to explain the IFRS adoption decision. Ramanna and Sletten (2009, p. 3) argue that "If the IASB is perceived as a European institution, countries that are culturally more distant from Europe are likely to be less accepting of IFRS." As a proxy for cultural closeness to Europe, they employ the proportion of a country's population that is Christian. They argue that "more Christian nations are more likely to be comfortable with European institutions like IFRS since Christianity in these countries is likely to have spread through colonization by European powers" (Ramanna and Sletten, 2009, p. 18). However, they are unable to empirically support their hypothesis relating the IFRS adoption decision to cultural closeness to Europe. In the current paper, we extend Ramanna and Sletten's work by measuring cultural differences across countries by employing Hofstede's (1980) widely used four cultural dimensions. Even after employing more refined measures of culture in our analysis, we are unable to document cultural influences on the IFRS adoption decision.

Even though Ramanna and Sletten $(2009$, p. 1) are unable to document a relationship between culture and the IFRS adoption decision, they provide empirical evidence "that more powerful countries are less likely to adopt IFRS, consistent with more powerful countries being less willing to surrender standard-setting authority to an international body." They measure country-level power as "the first principal component of a set of proxies for countries' abilities to influence international decision making (including their size and popularity with the United Nations)" (Ramanna and Sletten, 2009, p 4). Our results are consistent with this finding in that we document that larger countries, which presumably are more politically powerful than smaller countries, are less likely to adopt IFRS. Our results hold whether we measure country size by market capitalization or population.

While not directly examining cultural impacts on the IFRS adoption decision, Hope et al. (2006) also provide empirical evidence pertaining to the IFRS adoption decision. Specifically, Hope et al. (2006, p. 1) find that jurisdictions with "weaker investor protection mechanisms" and those that "are perceived to provide better access to their domestic capital markets" are more likely to adopt International Financial Reporting Standards.

This line of inquiry is relevant to international auditing firms since it is important for such firms to understand the divergent cultural forces that might drive countries to adopt (or not adopt) IFRS. As an example, individualism is one of Hofstede's (1980) cultural dimensions that we examine in this study. We hypothesize that countries in more individualistic cultures may be resistant to turning over the accounting standard setting process to an outside international body, while less individualistic cultures might more readily yield to an international standard setting body.

As multinational auditing firms make resource allocation decisions about their practice worldwide, they must understand the varied environments within which they operate. If IFRS convergence across the world leads to reduced costs for auditing firms, then cultures that are more likely to resist IFRS convergence efforts may present special challenges and/or opportunities to multinational auditing firms. On the one hand, cultural environments that are resistant to IFRS adoption may represent more costly investments for practice maintenance and growth. 
Auditors in such cultures would have to maintain their expertise in local GAAP, as well as IFRS expertise. They would not be able to rely solely on firm-wide training in a common accounting framework such as IFRS. Therefore, auditing in countries resistant to IFRS adoption efforts may create additional audit risk due to the "unique" accounting technical knowledge that would be required. Conversely, countries resistant to international accounting standards convergence may offer unique opportunities for revenue growth for accounting firms since additional fees could be charged to compensate the firms for their increased audit risk.

As capital markets continue to become more global, the world-wide adoption of IFRS would likely result in reduced transaction costs in these markets. However, global acceptance of IFRS is not yet a reality. In a practical sense, we want to know why universal acceptance has not yet occurred. We believe it is important to understand the potential sources of resistance against IFRS adoption. If cultural barriers to the adoption of IFRS can be identified, then strategies may be developed to help overcome these obstacles.

\section{HOFSTEDE'S CULTURAL DIMENSIONS AND HYPOTHESIS DEVELOPMENT}

Geert Hofstede (2009) has conducted a multi-year "comprehensive study of how values in the workplace are influenced by culture." Specifically,

From 1967 to 1973, while working at IBM as a psychologist, he collected and analyzed data from over 100,000 individuals from 50 countries and 3 regions. Subsequent studies validating the earlier results have included commercial airline pilots and students in 23 countries, civil service managers in 14 counties, 'up-market' consumers in 15 countries and 'elites' in 19 countries. From the initial results, and later additions, Hofstede developed a model that identifies four primary Dimensions to assist in differentiating cultures: Power Distance - PDI, Individualism IDV, Masculinity - MAS, and Uncertainty Avoidance - UAI. (Hofstede, 2009)

These four cultural dimensions have been utilized extensively in prior research efforts in accounting, management, business ethics, as well as other social sciences. International accounting examples include Gray's (1988) and Salter's (1995) examinations of how cultural differences have influenced the development of accounting systems in various countries, as well as Hope's (2003) and Archambault and Archambault's (2003) studies of culture's impact on corporate disclosure.

We will next describe each of the four cultural dimensions. Included in this discussion will be the development of a research hypothesis about how each cultural dimension should impact the decision about whether to adopt IFRS or to retain the present country-specific set of financial accounting and reporting standards.

\section{Power Distance (PDI)}

According to Hofstede and Hofstede (2005, p. 46), power distance is defined "as the extent to which the less powerful members of institutions and organizations within a country expect and accept that power is distributed unequally." In countries with high power distance there is a clear distinction between the roles of "subordinates" and "superiors." According to Williams and Zinkin (2008, p. 213), "Societies with high power distance expect to receive and take orders from authorities."

In the context of the IFRS adoption decision, the International Accounting Standards Board would likely be seen as an authoritative body in regards to the promulgation of international accounting standards. Our first hypothesis is therefore that high power distance countries will be more likely to yield control of accounting standard setting to an authoritative international body. Hypothesis 1 may be stated as:

H1: The greater power distance present in the culture, the more likely it is for that country to adopt IFRS.

\section{Individualism (IDV)}

Another of Hofstede's cultural dimensions is labeled Individualism; the opposite of Individualism is referred to as Collectivism. Hofstede and Hofstede (2005, p. 76) define these concepts as follows: 
Individualism pertains to societies in which the ties between individuals are loose: everyone is expected to look after himself or herself and his or her immediate family. Collectivism as its opposite pertains to societies in which people from birth onward are integrated into strong, cohesive in-groups, which throughout people's lifetimes continue to protect them in exchange for unquestioning loyalty.

Typically, individuals in collectivist societies (e.g., Japan) are concerned with the effect of a decision or action on the organization or on society at large. Conversely, individuals in more individualist societies (e.g., the United States or Canada) tend to consider the impact of actions and/or decisions on themselves or their immediate family.

In terms of the IFRS adoption decision, we postulate that highly individualistic countries will be reluctant to turn over control of the accounting standard setting process to an outside international organization, while collectivist societies would be more likely to yield to an international standard setting body. Our second hypothesis is therefore:

H2: The greater individualism present in the culture, the less likely it is for that country to adopt IFRS.

\section{Masculinity (MAS)}

Masculinity and its opposite Femininity comprise another of Hofstede's cultural dimensions. These constructs are defined as:

A society is called masculine when emotional gender roles are clearly distinct: men are supposed to be assertive, tough, and focused on material success, whereas women are supposed to be more modest, tender, and concerned with the quality of life. A society is called feminine when emotional gender roles overlap: both men and women are supposed to be modest, tender, and concerned with the quality of life. (Hofstede and Hofstede, 2005, p. 120)

In a highly masculine society, individuals would typically prefer autonomy over dependence on others. In addition, individuals would likely be adverse to following rules in high masculinity cultures, especially if those rules are mandated by an outside international organization such as the IASB. Our third hypothesis therefore is:

H3: The more masculinity is present is a society, the less likely it is for that country to adopt IFRS.

\section{Uncertainty Avoidance (UAI)}

A fourth cultural dimension that we will examine is labeled Uncertainty Avoidance. Hofstede and Hofstede (2005, p. 167) define uncertainty avoidance as "the extent to which the members of a culture feel threatened by ambiguous or unknown situations." Members of a society with high uncertainty avoidance would prefer familiar and stable situations to new and possibly unknown situations. Thus, if one seeks to avoid ambiguity and uncertainty, then one would prefer the status quo and would be resistant to change. We therefore hypothesize that countries with high uncertainty avoidance would be reluctant to change from their current country-specific set of accounting standards by adopting IFRS. Hypothesis 4 can be stated as follows:

H4: The more uncertainty avoidance present in the culture, the less likely it is for that country to adopt IFRS.

\section{Country Size}

Our fifth hypothesis relates the IFRS adoption decision to the size of the country. We hypothesize that larger countries will be more reluctant to adopt International Financial Reporting Standards than smaller countries. Larger countries would typically have well-developed and well-established financial accounting and reporting standards already in place. In such situations, it would be costly to abandon the current financial accounting and reporting system and replace it with IFRS. On the other hand, smaller countries (with presumably a less developed set of accounting standards) would find it cost effective to adopt an already developed comprehensive set of international accounting standards. Our fifth hypothesis may be stated as: 
H5: The larger the country, the less likely it is for that country to adopt IFRS.

\section{DATA, VARIABLE DEFINITIONS, AND EMPIRICAL RESULTS}

\section{Data and Variable Definitions}

We collected data on countries' IFRS adoption decisions by using the publicly available data source entitled iasplus.com, which is provided by Deloitte. Our data on IFRS adoption decisions is current since it reflects decisions as of September 21, 2009. Each country listed on iasplus.com is classified in one of the following four categories: IFRS required for all listed companies, IFRS required for some listed companies, IFRS permitted, or IFRS not permitted.

Table 1 lists the countries that constitute each category. The table indicates that a majority of the listed countries are in the "IFRS required for all" category. In particular, 85 of the 151 listed countries require International Financial Reporting Standards for all domestic listed companies. Included in this group are all of the European Union (EU) countries. The European Union has required the use of IFRS in the preparation of consolidated financial statements in all EU countries since 2005.

It is also interesting to note from Table 1 that many of the world's largest countries in terms of population (and/or market capitalization) are in the "IFRS not permitted" category. For example, China, India, and the United States currently do not allow IFRS for domestic companies. It is therefore likely that we will be able to empirically support our hypothesis that larger countries will be less likely to adopt IFRS.

Table 1: IFRS Adoption Decisions of 151 Countries

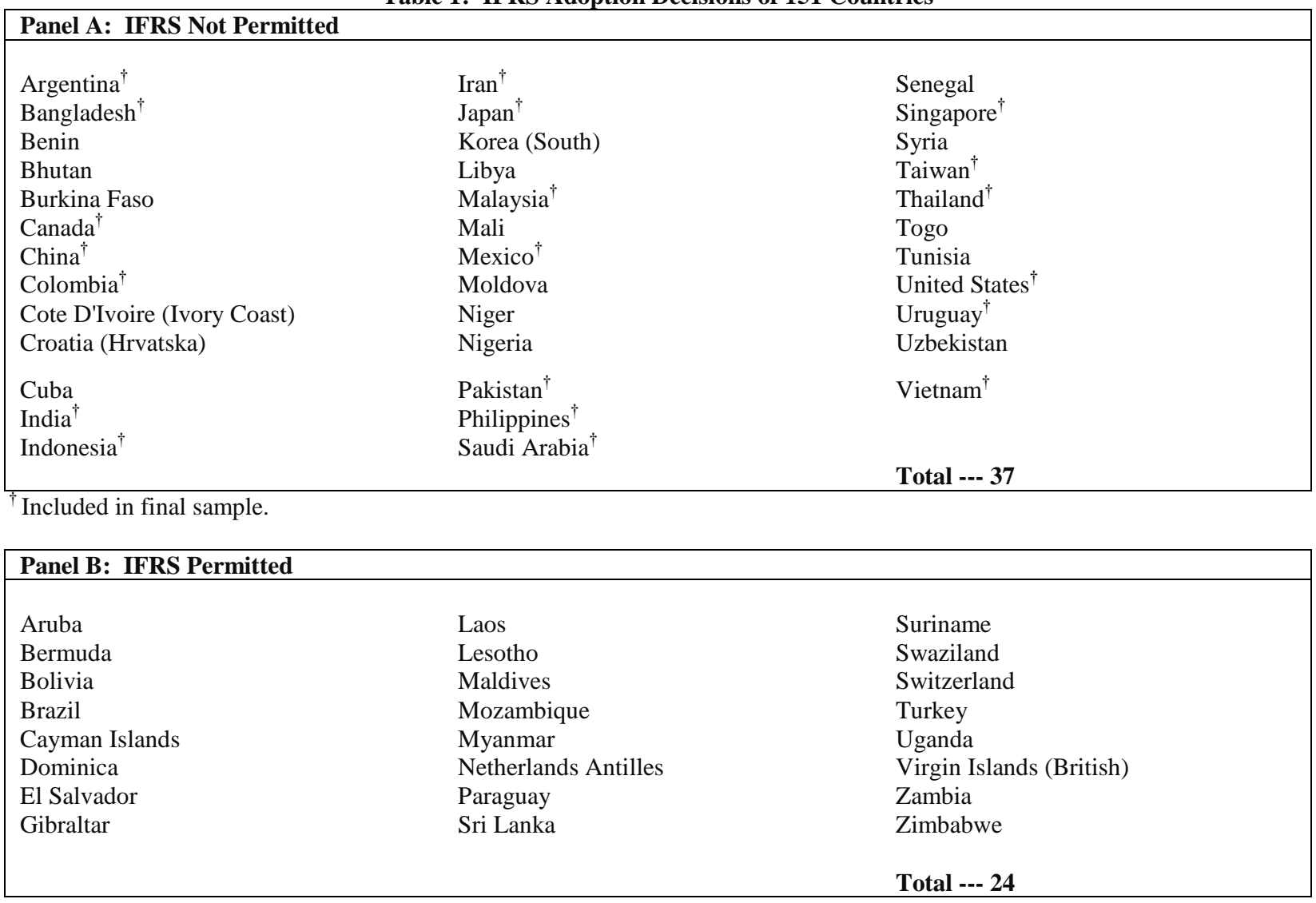




\begin{tabular}{|lll|}
\hline Panel C: IFRS Required for Some & & \\
\hline Azerbaijan & Israel & Russia \\
Belarus & Morocco & \\
& & Total --- 5 \\
\hline
\end{tabular}

\begin{tabular}{|c|c|c|}
\hline Abu Dhabi - U.A. E. & Greece $^{\dagger}$ & Namibia \\
\hline Anguilla & Grenada & Nepal \\
\hline Antigua and Barbuda & Guatemala & Netherlands ${ }^{\dagger}$ \\
\hline Armenia & Guyana & New Zealand ${ }^{\dagger}$ \\
\hline Australia $^{\dagger}$ & Haiti & Nicaragua \\
\hline Austria $^{\dagger}$ & Honduras & Norway $^{\dagger}$ \\
\hline Bahamas & Hong Kong $^{\dagger}$ & Oman \\
\hline Bahrain & Hungary $^{\dagger}$ & Panama $^{\dagger}$ \\
\hline Barbados & Iceland & Papua New Guinea \\
\hline Belgium $^{\dagger}$ & $\operatorname{Iraq}^{\dagger}$ & Peru $^{\dagger}$ \\
\hline Bosnia and Herzegovina & Ireland $^{\dagger}$ & Poland $^{\dagger}$ \\
\hline Botswana & Italy $^{\dagger}$ & Portugal $^{\dagger}$ \\
\hline Bulgaria $^{\dagger}$ & Jamaica $^{\dagger}$ & Qatar \\
\hline Chile $^{\dagger}$ & Jordan & Romania $^{\dagger}$ \\
\hline Costa Rica $^{\dagger}$ & Kazakhstan & Serbia (Republic of) \\
\hline Cyprus & Kenya $^{\dagger}$ & Slovak Republic \\
\hline Czech Republic ${ }^{\dagger}$ & Kuwait $^{\dagger}$ & Slovenia \\
\hline Denmark $^{\dagger}$ & Kyrgyzstan & South Africa ${ }^{\dagger}$ \\
\hline Dominican Republic & Latvia & Spain $^{\dagger}$ \\
\hline Dubai - U. A. E. & Lebanon $^{\dagger}$ & St Kitts and Nevis \\
\hline Ecuador $^{\dagger}$ & Liechtenstein & Sweden ${ }^{\dagger}$ \\
\hline $\mathrm{Egypt}^{\dagger}$ & Lithuania & Tajikistan \\
\hline Estonia $^{\dagger}$ & Luxembourg $^{\dagger}$ & Tanzania $^{\dagger}$ \\
\hline Fiji & Macedonia & Trinidad and Tobago \\
\hline Finland $^{\dagger}$ & Malawi & Ukraine \\
\hline France $^{\dagger}$ & Malta $^{\dagger}$ & United Kingdom $^{\dagger}$ \\
\hline Georgia & Mauritius & Venezuela $^{\dagger}$ \\
\hline Germany $^{\dagger}$ & Mongolia & \\
\hline Ghana $^{\dagger}$ & Montenegro & \\
\hline & & Total --- 85 \\
\hline
\end{tabular}

Included in final sample.

We employ a dichotomous dependent variable in our empirical tests. Specifically, our IFRS adoption decision variable is coded 1 (adopters) if a country is in the "IFRS required for all" category and 0 (non-adopters) if a country is in the "IFRS not permitted" group. We thus discard the two middle groups. It is not entirely clear whether countries in the "IFRS required for some" and "IFRS permitted" groups are in fact IFRS adopters or not. Ramanna and Sletten (2009) code their IFRS adoption decision variable in a slightly different manner. Similar to the methodology employed here, they classify the "IFRS required for all" group as adopters, while they characterize the "IFRS not permitted' group as non-adopters. However, instead of discarding the middle two groups as we do, they combine them into a group they call "partial adopters." Due to the relatively small number of countries in the middle two groups, and more importantly, due to the difficulties involved in properly classifying those two groups, we chose to discard them from the sample. However, as a sensitivity test, we reclassified the countries into three groups similar to Ramanna and Sletten, and the results were not qualitatively different from those reported here. Table 2 reveals that our sample is reduced by 29 countries after discarding the "IFRS required for some" and "IFRS permitted" countries. 
Table 2: Sample Selection Process

\begin{tabular}{|l|c|}
\hline Countries in full sample & 151 \\
Less countries with adoption rules permitting IFRS or requiring IFRS for some & $(29)$ \\
Less countries where culture variables are not available & $(56)$ \\
Less countries where market capitalization is not available & $(5)$ \\
Final sample used & 61 \\
\hline
\end{tabular}

We collected data on the four previously described cultural variables directly from the Hofstede (2009) website. Even though the Hofstede data has been widely used in prior research, the database does not contain complete culture data for many countries. Table 2 demonstrates that we lost an additional 56 countries from our sample due to missing culture data.

In our primary tests we employ a market capitalization variable as our proxy for a country's size. We collected data on market capitalization from the World Factbook website maintained by the United States Central Intelligence Agency (https://www.cia.gov/library/publications/the-world-factbook/rankorder/2200rank.html). Consistent with prior research, our market capitalization variable is defined as the natural logarithm of a country's total market capitalization, measured in millions. Due to missing market capitalization data, our sample is reduced by an additional five observations. As can be seen in Table 2, our final sample therefore consists of 61 countries with complete data regarding their IFRS adoption decision, cultural dimensions, and market capitalization. In Table 1 , we designate the 61 countries out of the 151 total countries on the iasplus database that are included in our final sample.

We employ a country's population as an alternative size proxy in order to test the sensitivity of our results to various measures of country size. We collected population data from the United Nations web site (http://www.un.org/esa/population/publications/wpp2008/wpp2008 text tables.pdf). Our population variable is defined as the natural logarithm of a country's population, measured in millions. We thus use a log transformation on both of our size proxies in an attempt to standardize the data, so that the extremely large countries do not unduly influence the results.

Table 3 provides some descriptive statistics on each of our cultural variables, as well as market capitalization, our primary size variable. The table indicates considerable cultural diversity across sample countries as evidenced by the wide range of values for each of the culture dimensions. For example, the Individualism variable among our sample countries has a low value of eight and a high value of 91. Sample countries with a high Individualism index include the United States (91) and Canada (80), while more Collectivist cultures include China (20) and Japan (46). The Masculinity index demonstrates a similarly wide range. As demonstrated in Table 3, the Masculinity variable ranged from five to 95 among our sample countries, with a mean value of 50 . Sample countries scoring high on the Masculinity index include Japan (95) and Italy (70). On the opposite end of the Masculinity scale were Sweden and Norway, with scores of five and eight, respectively.

Table 3: Descriptive Statistics

\begin{tabular}{|l|c|c|c|c|c|c|}
\hline & $\mathbf{N}$ & Range & Minimum & Maximum & Mean & Std. Deviation \\
\hline PDI & 61 & 93 & 11 & 104 & 59.25 & 20.543 \\
IDV & 61 & 83 & 8 & 91 & 44.11 & 24.112 \\
MAS & 61 & 90 & 5 & 95 & 50.20 & 17.613 \\
UAI & 61 & 104 & 8 & 112 & 63.85 & 23.329 \\
MKTCAP & 61 & 11.74 & 18.884 & 30.624 & 25.41 & 2.3877 \\
\hline
\end{tabular}

PDI is a country's power distance index.

IDV is a country's individualism index.

MAS is a country's masculinity index.

UAI is a country's uncertainty avoidance index.

MKTCAP is the natural logarithm of a country's total market capitalization, measured in millions. 
Table 4 provides an indication of the level of correlation among the four cultural dimensions, as well as country size (as measured by market capitalization) for our 61 sample countries. The table indicates only two significant correlations among our independent variables. The Individualism variable is significantly negatively correlated with the Power Distance variable and positively correlated with the market capitalization variable. Therefore, correlations among our independent variables should not be a major concern in our empirical tests.

Table 4: Correlations Among Independent Variables

\begin{tabular}{|l|c|c|c|c|c|}
\hline & PDI & IDV & MAS & UAI & MKTCAP \\
\hline PDI & 1 & $-.673^{* *}$ & .132 & .158 & -.237 \\
IDV & $-.673^{* *}$ & 1 & .052 & -.130 & $.459^{* * *}$ \\
MAS & .132 & .052 & 1 & .079 & .194 \\
UAI & .158 & -.130 & .079 & 1 & -.207 \\
MKTCAP & -.237 & $.459^{* *}$ & .194 & -.207 & 1 \\
\hline
\end{tabular}

PDI is a country's power distance index.

IDV is a country's individualism index.

MAS is a country's masculinity index.

UAI is a country's uncertainty avoidance index.

MKTCAP is the natural logarithm of a country's total market capitalization, measured in millions.

\section{Empirical Model and Results}

In order to test our hypotheses relating the IFRS adoption decision to cultural factors and country size, we employ logistic regression. As stated earlier, our dependent variable is dichotomous. It is coded 1 (adopters) if IFRS is required for all companies and 0 (non-adopters) if IFRS is not permitted. Since we utilize a dichotomous dependent variable, the resulting logistic regression model provides the likelihood of whether a country will adopt IFRS based on our culture and size variables. Our binomial logistic regression model is as follows:

Liklihood of Adoption $=\frac{1}{1+\mathrm{e}^{-\mathrm{z}}}$ where

$\mathrm{z}=\beta_{0}+\beta_{1}(\mathrm{EU})+\beta_{2}(\mathrm{PDI})+\beta_{3}(\mathrm{IDV})+\beta_{4}(\mathrm{MAS})+\beta_{5}(\mathrm{UAI})+\beta_{6}\left(\begin{array}{c}\mathrm{MKT} \\ \mathrm{CAP}\end{array}\right)$

where: $\quad$ EU is coded 1 if a country is a member of the European Union and 0 otherwise,

PDI is a country's power distance index,

IDV is a country's individualism index,

MAS is a country's masculinity index,

UAI is a country's uncertainty avoidance index,

MKTCAP is the natural logarithm of a country's total market capitalization, measured in millions.

We include a dummy variable for membership in the European Union in the model. As stated earlier, all EU countries have been required to use IFRS for their consolidated financial statements since 2005. Therefore the IFRS adoption decision has been made for EU countries as a condition of their membership in the EU. We thus include a control for European Union membership in the model. Ramanna and Sletten (2009) handle this issue by discarding EU countries from their sample. Including a dummy variable for EU membership in the model is statistically identical to eliminating the EU countries from the sample.

Table 5 provides our primary test results. The results indicate that the IFRS adoption decision is significantly negatively correlated with a country's size, as measured by market capitalization. Our hypothesis that larger countries are less likely to adopt International Financial Reporting Standards is therefore supported by the data. However, Table 5 indicates that none of the culture variables are significantly related to the IFRS adoption decision. We are thus unable to support our hypothesized relationships between cultural differences across countries and the IFRS adoption decision. 
Table 5: Results of Binomial Logistic Regression

\begin{tabular}{|l|c|c|}
\hline \multicolumn{1}{|c|}{ Variable } & $\boldsymbol{\beta}$ & Sig. \\
\hline Constant & 11.374 & .027 \\
EU & 21.051 & .998 \\
PDI & -.012 & .665 \\
IDV & .022 & .370 \\
MAS & -.009 & .753 \\
UAI & -.001 & .956 \\
MKTCAP & -.435 & .024 \\
\hline
\end{tabular}

Model:

Liklihood of Adoption $=\frac{1}{1+\mathrm{e}^{-\mathrm{z}}}$ where

$\mathrm{z}=\beta_{0}+\beta_{1}(\mathrm{EU})+\beta_{2}(\mathrm{PDI})+\beta_{3}(\mathrm{IDV})+\beta_{4}(\mathrm{MAS})+\beta_{4}(\mathrm{UAI})+\beta_{6}(\mathrm{MKTCAP})$

Where: $\quad$ EU is coded 1 if a country is a member of the European Union and 0 otherwise.

PDI is a country's power distance index.

IDV is a country's individualism index.

MAS is a country's masculinity index.

UAI is a country's uncertainty avoidance index.

MKTCAP is the natural logarithm of a country's total market capitalization, measured in millions.

In Table 6, we assess the sensitivity of our results to an alternative measure of country size. The results in Table 6 are consistent with our primary test results. In particular, the table reveals that the IFRS adoption decision is negatively associated with a country's size, where size is defined as the natural logarithm of a country's population, measured in millions. Also consistent with our primary tests, the four culture variables are not significantly related to the IFRS adoption decision. Thus our results are not sensitive to our definition of country size.

Table 6: Results of Binomial Logistic Regression

\begin{tabular}{|l|c|c|}
\hline \multicolumn{1}{|c|}{ Variable } & $\boldsymbol{\beta}$ & Sig. \\
\hline Constant & 17.163 & .009 \\
EU & 20.373 & .998 \\
PDI & .007 & .814 \\
IDV & .012 & .627 \\
MAS & -.009 & .774 \\
UAI & .017 & .408 \\
POP & -1.084 & .005 \\
\hline
\end{tabular}

Model: Liklihood of Adoption $=\frac{1}{1+\mathrm{e}^{-\mathrm{z}}}$ where

where:

$$
\mathrm{z}=\beta_{0}+\beta_{1}(\mathrm{EU})+\beta_{2}(\mathrm{PDI})+\beta_{3}(\mathrm{IDV})+\beta_{4}(\mathrm{MAS})+\beta_{4}(\mathrm{UAI})+\beta_{6}(\mathrm{POP})
$$

EU is coded 1 if a country is a member of the European Union and 0 otherwise.

PDI is a country's power distance index.

IDV is a country's individualism index.

MAS is a country's masculinity index.

UAI is a country's uncertainty avoidance index.

POP is the natural logarithm of a country's total population, measured in millions. 


\section{CONCLUSIONS, IMPLICATIONS, AND SUGGESTION FOR FUTURE RESEARCH}

The global adoption of, or at least convergence with, International Financial Reporting Standards experienced significant positive momentum for most of the present decade. In fact, it seemed that the world-wide acceptance of IFRS was inevitable. Initiating this momentum most significantly, the European Union called for the adoption of IFRS for listed companies in 2002. Following through on this earlier commitment, in 2005 almost 7,000 companies in some $25 \mathrm{EU}$ countries switched from their local accounting standards to IFRS (IASB, 2009).

Additionally, China, while not formally adopting IFRS, implemented a set of accounting standards in 2006 that were significantly congruent with IFRS (IASB, 2009). Similarly, while not directly submitting to IASB authority, Brazil, Canada, Chile, Japan, and South Korea have each recently established timelines to either adopt or converge with IFRS over the next several years. The U. S. Securities and Exchange Commission (SEC) now allows foreign registrants on U.S. stock exchanges to publish financial statements using IFRS without the need to provide a reconciliation to U.S. Generally Accepted Accounting Principles (IASB, 2009). In 2008, the SEC went further and proposed a timeline for the adoption of IFRS by listed U.S. domestic companies. This timeline is often referred to as the SEC's IFRS “roadmap."

Even with all of this positive early momentum toward world-wide IFRS acceptance, the results of this paper indicate that as of late 2009 a significant number of countries have yet to adopt IFRS. At the present time, it seems that standard setters in many of the non-adopting countries may delay their so-called timelines or roadmaps toward IFRS adoption. In some cases, there are now questions about when, and maybe even if, IFRS will eventually be adopted.

In the current paper, we explore possible reasons why countries might choose to adopt or not adopt International Financial Reporting Standards. We are unable to empirically support our hypotheses relating the IFRS adoption decision to differences in culture across countries. Prior research findings are consistent with this result. There are two possible reasons for the lack of association between culture and the IFRS adoption decision. One alternative is that our empirical measures of culture do not adequately measure cultural diversity across countries. Even though the Hofstede data is widely used, the empirical validity of the four culture dimensions has been criticized. It is therefore possible that we have a construct validity problem with our culture variables. The other alternative is simply that no association exists between the IFRS adoption decision and culture. We view the latter alternative as more likely since we are not alone in our inability to document a significant association between cultural diversity and the IFRS adoption decision.

However, we do find that the IFRS adoption decision is negatively associated with country size. Our results are consistent, regardless of how we define country size. Neither is this result sensitive to alternative specifications of countries as "adopters" or "non-adopters." As evidenced in our Table 1, many of the largest countries in the world such as the United States, China, and India have not adopted International Financial Reporting Standards.

It is our view that this negative relationship between country size and IFRS adoption likely reflects a general feeling of satisfaction among large countries with their current domestically developed accounting standards. In other words, many of the world's largest countries would likely not feel an urgent obligation to incur the costs to change from their current standards in order to conform to an international standard setting body. While the international standards may be well-designed standards, they do not capture the unique aspects of any country's economic and financial reporting environment. Given that most large countries already have well-established and well-developed financial accounting and reporting systems in place, it would seem unlikely that they would be in a rush to change to a system that might not meet the needs of the companies in the country as well as the domestically developed financial accounting and reporting standards. In addition, one of the purported benefits of IFRS is that IFRS allows for easier access to foreign capital markets. However, companies in countries with large capital markets might not have a great need to access foreign capital markets. Therefore, the existence of a large domestic capital market might lessen the need to switch to IFRS for large countries. 
We might also be able to explain this negative size effect by suggesting that the political nature of accounting standard setting may be at play here. For example, in a large country such as the United States, the Financial Accounting Standards Board has a great number of constituents to whom it has to answer. These constituents, including the SEC, Congress, business, public accounting, and academia all have very diverse, and recently mutating positions on the adoption of IFRS. It seems plausible then that a change as dramatic as the adoption of a different set of accounting standards promulgated by a foreign body such as the IASB is likely to be more difficult. Perhaps a primary issue in this regard is that such constituents, especially Congress and the SEC will have to substantially relinquish control of the standard setting process if the U.S. adopts IFRS outright. While China and India have perhaps less diverse societies than the U.S., it seems plausible that their standard setters, and the political forces behind them, would also be reluctant to relinquish control of the standard setting process to a foreign entity. This seems especially plausible in a command-based political system such as China. It seems more plausible that if these large countries progress toward IFRS, they may accomplish this via convergence rather than outright adoption in order to retain ultimate standard setting authority.

We have some suggestions for future research in this area. Given that it is likely that additional countries will adopt, or at least converge their accounting standards with IFRS in the coming years, it seems fruitful to replicate this study in two or three years to see if the negative relationship between country size and IFRS adoption still holds. Such research seems particularly useful given the recent deceleration of adoption and convergence efforts brought on by the financial crisis and recession of the past 18 months. If the results remain unchanged, that would be a good indication of the continued reluctance of large countries to yield standard setting authority to an international organization. Another suggestion for future research activity would be to re-examine the impact of culture on the IFRS adoption decision by developing alternative empirical measures of cultural diversity. Finally, it seems fruitful to examine the large non-adopters via a case study approach to try and explain their standard setters' decision to not adopt IFRS presently or at least to explain why they may have not adopted IFRS as quickly as some of the early adopters, such as the EU and other British Commonwealth countries.

\section{AUTHOR INFORMATION}

Curtis Clements, Ph.D., CPA, is an associate professor of accounting at Abilene Christian University and has published articles in the Journal of Business Ethics, Journal of Accounting and Public Policy, Journal of Information Systems, Internal Auditing, and Strategic Finance.

John D. Neill, Ph.D., CPA, is a professor of accounting at Abilene Christian University and his publications include articles in the Journal of Business Ethics, Corporate Governance: An International Review, Journal of Accounting Literature, Accounting Horizons, Journal of Applied Business Research, the Financial Analysts Journal, and the Journal of Accounting, Ethics, and Public Policy.

O. Scott Stovall, Ph.D., is an associate professor of accounting at Abilene Christian University and has published articles in the Journal of Business Ethics, Corporate Governance: An International Review, Journal of Applied Business Research, Management Accounting Quarterly, and The Journal of Accounting Case Research.

\section{REFERENCES}

1. Archambault, J. J. and M. E. Archambault: 2003. "A Multinational Test of Determinants of Corporate Disclosure", The International Journal of Accounting 38(2): 173-194.

2. Clements, C., Neill, J. and O. Stovall: 2009a. "An Analysis of International Accounting Codes of Conduct”, Journal of Business Ethics 87: 173-183.

3. Clements, C., Neill, J. and O. Stovall: 2009b. "The Impact of Cultural Differences on the Convergence of International Accounting Codes of Ethics", Journal of Business Ethics, forthcoming.

4. Doupnik, T., and G. Tsakumis: 2004. "A Critical Review of Tests of Gray's Theory of Cultural Relevance and Suggestions for Future Research", Journal of Accounting Literature 23: 1-48.

5. Gray, S. J.: 1988. "Towards a Theory of Cultural Influence on the Development of Accounting Systems Internationally", Abacus 24(1): 1-15. 
6. Hofstede, G.: 2009. 'Geert Hofstede Cultural Dimenstions', [Online] available at http://www.geerthofstede.com/hofstede dimensions.php.

7. Hofstede, G. and G. J. Hofstede: 2005, Cultures and Organizations, (McGraw-Hill: New York).

8. Hofstede, G.: 1980. Culture's Consequences. Sage Publications: Beverly Hills, CA.

9. Hope, O., Justin, J. and T. Kang: 2006. "Empirical Evidence on Jurisdictions that Adopt IFRS", Journal of International Accounting Research 5(2): 1-20.

10. Hope, O. : 2003. "Disclosure Practices, Enforcement of Accounting Standards, and Analysts' Forecast Accuracy: An International Study", Journal of Accounting Research 41(2): 235-272.

11. IASB: 2009. "Who We Are and What We Do", International Accounting Standards Board, IASC Foundation, (July 13): Available at: http://www.iasb.org/About+Us/International+Accounting+Standards+Board+-+About+Us.htm.

12. Ramanna, K. and E. Sletten: 2009, "Why do Countries Adopt International Financial Reporting Standards", Working Paper, Harvard Business School.

13. Salter, S. B.: 1995. "Cultural Influence on the Development of Accounting Systems Internationally: A Test of Gray's (1988) Theory”, Journal of International Business Studies 26(2): 379-397.

14. Williams, G. and J. Zinkin: 2008, 'The Effect of Culture on Consumers' Willingness to Punish Irresponsible Corporate Behaviour: Applying Hofstede's Typology to the Punishment Aspect of Corporate Social Responsibility', Business Ethics: A European Review 17(2), 210-226. 